\title{
The Subjective Experiences of Two Heroin Addicts Who were Taught Kundalini Yoga While Incarcerated
}

\author{
Melvin L Morse* \\ University of Washington, USA
}

Submission: March 01, 2019; Published: March 12, 2019

*Corresponding author: Melvin L Morse, Wilmington University, Sussex Correctional Institution, Georgetown, Delaware 19947, Institute for the Scientific Study of Consciousness, Recidivism Prevention Group, 89 Big Sky Drive, Leicester, USA

\begin{abstract}
Yoga and meditation have been shown to be successful in both heroin addiction and in prison populations in preventing both relapse and recidivism. Such strategies are best when there is a non-duality present between the helper and the "helped" and there are comprehensive programs which incorporate both prisons based and community programs. However, the current disease-based understanding of heroin addiction has not led to robustly successful treatment strategies for either prevention of relapse or recidivism in incarcerated addicts. This report presents two cases of addicted inmates who learned meditation and Kundalini yoga while incarcerated which led to spiritual transformation with resultant behavioural changes. The author suggests that a different model for heroin addiction based on understanding that addicts often have shattered childhoods which directly leads to dysfunctional learning styles which interfere with the problem solving necessary for healthy relationships, avoiding addiction, and the mental discipline necessary for employment. Learning yoga and meditation can lead to a change in thinking strategies and spiritual understandings which in turn lead to life affirming healthy lifestyles.
\end{abstract}

There is currently a dearth of understand the inner life of the incarcerated addict and how that changes with the practice of yoga and meditation. Understanding this inner life can break down the dualistic barriers between the helpers and the "helped" which is documented as an essential component to successful addiction treatment and re-entry recidivism prevention programs.

Keywords: Recidivism; Heroin addiction; Meditation; Kundalini yoga; Melvin Morse; Melvin morse MD; Treatment; Spiritual transformation; Transformation

\section{Introduction}

Two inmates at Sussex Correctional Institution who were addicted to heroin were taught kundalini yoga which they practiced on a regular basis. Their practice gave them a different perspective on their inner perception of spirituality and the meaning of their lives. This in turn reduced their cravings for heroin and directly led to a cessation of addictive behaviour. Two years after release from prison, they remain gainfully employed and continue to practice meditation and kundalini yoga on a regular basis. Both yoga and meditation have been shown to reduce recidivism [1] and improve mood, behavioural and cognitive functioning in prisoners. [2] Additionally, yoga and meditation have been helpful in the treatment of heroin addiction. [3] However, recidivism rates in the United States are as high as $75 \%$ within five year after release [4]. Heroin addiction is endemic and deaths from heroin overdoses are at a crisis level. [5] One recent review of the use of meditation and yoga in prison populations emphasizes that in order for these programs to prevent recidivism, there must be a "non-duality" between the helper and the helped", meaning the volunteers who teach yoga and meditation and the prisoners. Over half of inmates in prisons have a substance abuse disorder.
The authors further emphasis the need for the building of meditation communities both inside and outside of prison [6]. There is a dearth of understanding in both the therapeutic community and the general public (who potentially fund prison intervention programs) of the subjective experiences of heroin addicts and how they respond to yoga and meditation programs. These understandings are essential to lessen the current societal belief in the duality of "criminals who are addicts" and the rest of society. These two case reports present the subjective experiences of heroin addicts and how they were transformed by the regular practice of yoga and meditation.

The book Unbroken Brain: A Revolutionary New Way of Understanding Addiction [7] presents a novel model of addiction as learning disorder caused by the effects of shattered childhoods resulting in dysfunctional learning to avoid bad outcomes and problem solve effectively. Ms Szalavitz documents that treatment success rates using treatment techniques based on the current medical model for addiction are extremely low. Some studies show positive outcomes of rehabilitation programs as low as $10 \%$ after one year. 
The author of this paper, in his workwith dozens of incarcerated heroin addicts agrees that most of them do not simply have dysfunctional families but rather have had shattered childhoods. As a result, even the most basic spiritual understandings are foreign to these incarcerated heroin addicts, which in turn adversely impacts their meaning of life and consequently contributes to recidivism, the inability to be regularly employed or have healthy life affirming relationships. Learning yoga and meditation can dramatically transform spiritual understandings into life affirming basis core values which in turn leads to reduced recidivism. Furthermore, both yoga and meditation can replace addictive cravings and give addicts concrete ways of handling triggers for relapse.

\section{Case Reports}

Note: The author has received Level One teacher training, a 220 professional certification program taught by instructors accredited by the Kundalini Research Institute.

\section{Case 1}

Roger was a 36-year-old heroin addict who spent most of his adult life in prison for burglary related crimes. He describes his drug as "It is the best feeling in the world. There is no high, no experience like it. I feel like Spiderman, He Man and Batman all at once when I shoot heroin. I love the feeling." He has numerous scars behind his knees, elbows and neck from injections. He cannot describe any childhood memories of unconditional love, feeling safe, or being nurtured by loving caretakers. His childhood experiences are uniformly horrific consistent with a shattered childhood. He states "what a sad pathetic life I have had. I partied for three days straight and then stuck a gun in my mouth. I cried in anger because I didn't have the guts to pull the trigger. I don't know why I call it partying. It is not a party. Eventually after you have taken heroin for so many years, you just want to die".

The author has heard many non-addicts describes pleasurable activities, even intense ones such a bungee jumping, mountain climbing, receiving prestigious awards, and sports activities and yet he has never heard anything as intense and pleasurable as the heroin or even methadone high. It is no wonder that Roger can describe waking up after seven days of nonstop heroin use filthy in a room with no electricity or water, covered with feces and rat droppings and only thinking that he wants to get high again. In his many years in prison, Roger refused to take any classes such as GED classes. He currently was sentenced to 15 years in prison, all of which would be suspended if he could successfully complete the prison drug treatment program. He failed twice so far.

Kundalini Yoga was an excellent choice for him as it involves active meditation involving hand movements, eye movements and chanting. Roger is too physical to simply sit and learn to quiet his mind. In addition, he regularly journaled his emotions and thoughts. He learned to visualize having out of body experiences. Within three months he was transformed. He spontaneously developed a belief that he had a source of wisdom within himself that he called God. This was not part of his yoga training but a by-product of it. While in a meditative state induced by hand movements and chanting, he stated that "something stirred in my heart, my soul. I felt that I lit a candle in a very desolate place".

He successfully completed the prison's drug treatment program and received his GED. Instead of his typical negative thought processes and violent inner mental landscape, he would make statements such as "I love all the guys (his fellow inmates). Love is my karma. If someone needs something, of course I will help them (if I can). I have completely changed. It used to be that even after (five years in prison) I would still crave heroin. Now I never think about it. Drugs are never on my mind. I look at my scars and I am ashamed. I can't believe that I ever injected drugs. Roger has five children with three different women. He has a different sense of family and actively wants to be a father and is trying to problem solve his complex relationships. He states "at least I won't lie to them. My Mom always lied to me, I want to be different". Two years after his release he remains employed in an automobile autobody shop.

\section{Case 2}

James is 28 . He stated using heroin at age 22 . He has 8 pages of criminal convictions. As far back as he can remember, he has been miserable. His father was a 60 -year-old man who had a brief relationship with his mother. At age 10 , he attempted suicide by overdosing on various pills he found in his home. He was taken to the hospital in handcuffs, something of which he has a vivid memory. At age 17, he again attempted suicide. He dropped out of school in the ninth grade to make money dealing drugs and stealing. He has three children, one of whom is autistic, who are cared for by his mother. When first learning meditation, James could only attempt to control his breathing, in several short sessions a day, typically less than one minute. His inner landscape typically drifted to his failures, fears, and mental reliving of pleasurable drug experiences.

Over time he was able to accomplish some of the Kundalini routines for as long as 5-10 minutes. He states "I learned to reward myself when my mind was finally clear. I learned to listen (to his inner dialogue) but not speak to myself". After two months he had a startling breakthrough. He thought that he was talking with something within himself that "is all of creation". It was not a verbal dialogue but an exchanging of sensations. He describes it as "a truth that could not be denied". He states "I heard 'keep on going, you are on the right path for you' ". This experience restructured his sense of meaning of life. He believed that all that he had experienced was in fact required for him to have a meaningful life. He states that he has done "evil" in his life, but now is at peace with it and has learned from it. He spontaneously developed that Buddhist concept that anything that creates suffering is evil.

He began to both classically meditate in a seated posture as well as practicing Kundalini exercises. He describes his meditation as "accessing a single thread on the Universal sweater". He states 
that he uses meditation to open a channel to my Creator. If we open that channel, it speaks louder and louder until we have to change our lives. But this voice only speaks love." Three years after his release he continues his meditative practices, is gainfully employed and is free from substance abuse.

\section{Discussion}

Spiritual transformation is an overlooked tool in the treatment of heroin addiction and the prevention of recidivism. The author believes that this is because it is not well appreciated that a shattered child hood directly leads to dysfunctional spiritual values and a lack of meaning of life. In turn, these dysfunctional core values contribute to addiction, dysfunctional relationships and a lack of the mental discipline required for regular employment.

In both of these cases, a transformation of spiritual values coupled with a profound change in the meaning of life preceded changes in behaviour. Understanding addiction as a disease process has not as yet led to success in treating addiction and preventing recidivism in drug addicted inmates. Using a model framing addiction and criminal behaviour as learned response to the disrupted spiritual and moral development inherent in a shattered childhood provides a pathway to transforming one's internal mental architecture through learning new skills and

This work is licensed under Creative

Commons Attribution 4.0 License

DOI: $10.19080 / J Y P .2019 .06 .555700$ developing regular spiritual practices. This transformation can be facilitated through meditation and yoga and may explain their well-documented benefits in treating addiction and preventing recidivism. These effects will become more robust with the establishment of yoga and meditation communities which seamlessly integrate prison-based programs with existing reentry job training and drug treatment community-based programs for the ex-incarcerated.

\section{References}

1. Pashupati SL, Jagat Bandhu JG (2008) Low Reincarceration Rate Associated with Ananda Marga Yoga and Meditation. International Journal of Yoga Therapy 18(1): 43-48.

2. Kerekes N, Fielding C, Apelqvist S (2017) Yoga in Correctional Settings: A Randomized Controlled Study. Frontiers in Psychiatry 8: 204.

3. Khalsa SB, Khalsa GS, Khalsa HK, Khalsa MK (2008) Evaluation of a residential Kundalini Yoga lifestyle pilot program for addiction in India. J Ethn Subst Abuse 7(1): 67-79.

4. (2014) Bureau of Justice Statistics April, Press release.

5. Overdose Death Rates: National Institute on Drug Abuse.

6. Lyons T, Cantrell WD Prison (2016) Mediation Movements and Mass Incarceration. Int J Offender Ther Comp Criminol 60 (12): 1363-1375.

7. Szalavitz M (2017) Unbroken Brain: A Revolutionary New Way of Understanding Addiction. Picador, MacMillan.

Your next submission with Juniper Publishers
will reach you the below assets
- Quality Editorial service
- Swift Peer Review
- Reprints availability
- E-prints Service
- Manuscript Podcast for convenient understanding
- Global attainment for your research
- Manuscript accessibility in different formats
( Pdf, E-pub, Full Text, Audio)
- Unceasing customer service
Track the below URL for one-step submission
https://juniperpublishers.com/online-submission.php

